\title{
Preparation, Characterization and In Vitro Drug Release Studies of 6-mercaptopurine Thin Film
}

\author{
Prem Kumar $\mathrm{G}^{{ }^{*}}$, Jagadeesh S. Sanganal ${ }^{1}$, Manohara $\mathrm{C}^{1}$, Swamy $\mathrm{KB}^{1}$, Aparna $\mathbf{V}^{1}$, \\ Shridhar NB ${ }^{1}$, Narayana Swamy HD $^{2}$, Ramachandra $\mathrm{SG}^{3}$ and Phani $\mathrm{AR}^{4}$ \\ ${ }^{1}$ Department of Veterinary Pharmacology and Toxicology, Veterinary College, Bangalore, Karnataka, India \\ ${ }^{2}$ Department of Veterinary Pathology, Veterinary College, Bangalore, Karnataka, India \\ ${ }^{3}$ Central Animal Facility, Indian Institute of Science, Bangalore, Karnataka, India \\ ${ }^{4}$ Nano-RAM Technologies, Bangalore, Karnataka, India
}

\begin{tabular}{ll}
\hline \multicolumn{1}{c}{ Abstract } & Article Information \\
\hline Oral thin films of 6-mercaptopurine were fabricated from mucoadhesive polymer, & Article History: \\
chitosan and polyvinylpyrrolidone for the purpose of prolonging drug release and & Received :20-02-2014 \\
improving its bioavailability. All fabricated film formulations prepared were smooth & Revised $: 25-06-2014$ \\
and translucent, with good flexibility. The weight and thickness of all the & Accepted :28-06-2014 \\
\cline { 2 - 2 } formulations were found to be uniform. These films were also evaluated for surface & Keywords: \\
$\mathrm{pH}$, folding endurance, swelling percentage (\% S) and in vitro disintegration time. & 6-mercaptopurine \\
Scanning Electron Microscopy (SEM) and Fourier Transform Infrared (FTIR) were & In Vitro Drug Release \\
used to evaluate the physico-chemical nature of the films. In-vitro drug release have & SEM \\
shown enhanced release profiles for thin films compared to pure drug and the & FTIR \\
\cline { 2 - 2 } release patterns have been found to be pH dependant. The results of the study & *Corresponding Author: \\
reveals that fabrication of 6-MP oral thin film by using solvent cast technology is a & Prem Kumar G \\
simple and an efficient method for drug delivery to achieve desired therapeutic & \\
compliance. & \\
&
\end{tabular}

\section{INTRODUCTION}

The thiopurines, azathioprine, 6-mercaptopurine and 6-thioguanine are effective immune-suppressants and anti-cancer agents and are prescribed increasingly to treat inflammatory diseases (Estlin, 2001). 6-mercaptopurine (6-MP) was approved as an antitumor drug by Food and Drug Administration (FDA) in 1953 (Cuin et al., 2011) and has been widely used in the treatment of Acute Lymphoblastic Leukemia and Acute Myelocytic Leukemia (Sun et al., 2013; Karim et al., 2013) and other diseases such as rheumatologic disorders, prevention of rejection following organ transplantation, systemic lupus erythematosus, non-Hodgkin-lymphoma, inflammatory diseases (Crohn's Syndrome and Ulcerative Colitis) and so on (Podsiadlo et al., 2008; Kevadiya et al., 2013).

6-MP is first metabolized to an active form methylated thioinosinic acid (MeTIMP) by hypoxanthine phosphoribosyltransferase (HPRT) within cell to inhibit de novo purine synthesis (Panetta et al., 2006) and later converted to thioguanine, which is a DNA intercalating agent. However, 6-MP undergoes extensive first pass catabolism by $\mathrm{XO}$ (Xanthine oxidase) and TPMT (thiopurine $S$ methyl transferase) limiting their bioavailability. So this could lead to a lower bioavailability (about 16\%) (Cheok and Evans, 2006), short plasma halflife (0.5-1.5 h) (Zacchigna et al., 2007), with moderate

plasma protein binding (19\% to $30 \%$ ) (Mawatari et al., 2001) and plummeting chemotherapeutic effect. With a view to optimize the therapeutic effect of 6-MP, the objective of this investigation was to formulate mucoadhesive buccal films using chitosan-Polyvinyl pyrolidone (PVP) polymer complex for sustained release of the drug and to evaluate their physico-chemical characteristics by using SEM and FTIR.

\section{MATERIALS AND METHODS \\ Materials}

6-mercaptopurine monohydrate (Assay purity $\geq 98.0 \%$ ), Polyvinyl Pyrrolidine (PVP) (Mw= 13,00, 000), Chitosan low molecular weight (deacetylation $\geq 75.0 \%$ ), Acetic acid glacial $(\geq 99.85 \%)$ and dialysis tubing cellulose membrane were purchased from Sigma-Aldrich Chemical Co. Ltd. Monobasic sodium phosphate $\left(\mathrm{NaH}_{2} \mathrm{PO}_{4}\right)$ and Dibasic sodium phosphate $\left(\mathrm{Na}_{2} \mathrm{HPO}_{4}\right)$ were purchased from Emplura $^{\circledR}$, Merck Specialities Pvt. Ltd., Bangalore, India.

\section{Preparation of Chitosan-PVP oral thin films}

Chitosan solution $(2 \% \mathrm{w} / \mathrm{v})$, was prepared by dissolving chitosan in $1 \% \mathrm{w} / \mathrm{v}$ acetic acid and then 6 mercaptopurine $(0.5 \% \mathrm{w} / \mathrm{v})$ was dispersed in the solution under constant magnetic stirring. PVP solution $(2 \% \mathrm{w} / \mathrm{v})$, was prepared by dissolving PVP in ethanol by stirring it 
Prem Kumar et alo,

continuously for about $10 \mathrm{mnt}$ to obtain clear homogeneous solution. Chitosan-PVP blends solutions (1:2) were prepared by stirring for about half an hour. The obtained homogenous solutions were poured into a plastic mould, covered and kept overnight at room temperature for solvent evaporation. The resulting films were used for further physico-chemical analysis.

\section{Chitosan-PVP Oral Thin Film Characterization Scanning Electron Microscopy (SEM)}

The surface morphology of the oral thin films containing drug and polymer were characterized by Field Emission Scanning Electron Microscope (FESEM, FEI Sirion) at operating voltage of 5-30 KV. All images were recorded at working distance of $8-10 \mathrm{~mm}$.

\section{FTIR Analysis}

The procedure involving sample preparation and spectral recordings was carried out by previously described method (Stuart et al., 2004). IR spectra of 6MP, PVP and oral films were recorded using FTIR Nicolet 6700 (Thermo Fisher Scientific, Madisson, WI, USA) operated by Omnic software 8.1. In particular, for oral thin films measurement the spectra were obtained by attenuated total reflectance (ATR) method using smart orbit diamond ATR. Briefly, the formulations were placed individually on the sample plate of the smart orbit and screwed lightly to record IR spectra in ATR mode.

\section{Surface $\mathrm{pH}$}

The surface $\mathrm{pH}$ of 6-mercaptopurine oral thin films was evaluated by using combined $\mathrm{pH}$ electrode. Films were moistened with milli-Q- water and $\mathrm{pH}$ was measured at the interphase of water and film (Prem et al., 2014).

\section{Thickness}

Thicknesses of these films were measured by calibrated digital Vernier callipers (Mitutoyo 550-203-10, Mitutoyo, Japan). Thickness was measured at four different points in the films and mean value was expressed (Raju et al., 2011).

\section{Folding Endurance}

Folding endurance was determined by repeatedly folding the film $(4 \times 4 \mathrm{~cm})$ at the same point until a breaking point was achieved. Number of times the film could be folded at the same point without breaking was considered as folding endurance value. All the tests were performed four times and mean of the values was reported (Mona et al., 2012).

\section{Swelling Percentage (\% S)}

Swelling index for the films was estimated in simulated salivary fluid at $\mathrm{pH} 6.8$. Briefly, films (surface area $4 \mathrm{~cm}^{2}$ ) were weighed and transferred onto a petriplate containing buffer media (Wang et al., 2000). At definite time interval (15s), films were removed, blotted quickly with adsorbent paper, and then weighed. The percentage of water uptake was calculated as follows where $W_{f}$ is the weight of wet grafted films and $\mathrm{W}_{\mathrm{i}}$ is the weight of dry grafted films.

$$
\% S=\frac{\left(W_{f}-W_{i}\right)}{-W_{i}} \times 100
$$

\section{In Vitro Disintegration Time}

In vitro disintegration time was measured by following monograph from United States Pharmacopeia (USP) using disintegration test apparatus (LABINDIA, DS8000) (United States Pharmacopoeia, 2009).
Sci. Technol. Arts Res. J., April-June 2014, 3(2): 63-67

\section{Drug Content}

A sample of $3 \mathrm{~cm}^{2}$ was dissolved in $10 \mathrm{ml}$ methanol by vortex for 5 minute to extract drug from film and filtered through whatman filter paper and analyzed spectrophotometrically at $325 \mathrm{~nm}$ using methanol as a blank (Senthil et al., 2010).

\section{In Vitro Drug Release}

In vitro drug release studies were performed using

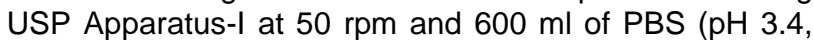
6.4 and 7.4 ) at $37 \pm 0.5^{\circ} \mathrm{C}$. A calculated $10 \mathrm{mg}$ (conc. $2 \mathrm{mg} / \mathrm{ml}$ ) of pure drug and Chitosan-PVP thin film were separately placed in dialysis tube and immersed in PBS at above mentioned $\mathrm{pH}$. At predetermined time intervals $(0$, 15, 30 min, 1 h, 2 h, 3 h, 4 h, 8 h, 12 h, 16 h, 24 h and 48 $\mathrm{h}$, an aliquot of $4 \mathrm{ml}$ of the release media was withdrawn and the concentration of the drug in release media was estimated by UV spectroscopy (Evolution 300; Thermo Fisher Scientific, USA) at $325 \mathrm{~nm}$. The dissolution medium was replaced with fresh buffer $(4 \mathrm{ml})$ to maintain constant total volume (Manohara et al., 2014).

\section{RESULTS AND DISCUSSION \\ Physico-chemical Characterization \\ SEM Analysis}

The prepared oral thin film of 6-MP is depicted in Figure 1. Scanning electron micrographs of the 6-MP thin film with low and high magnification images are depicted in the Figure $2 a$ and $2 b$ respectively. The diameter $(500 \mathrm{~nm}-2 \mu \mathrm{m})$ of the distributed 6-MP microparticles in the film has been confirmed (Image software, provided by National Institutes of Health, USA).

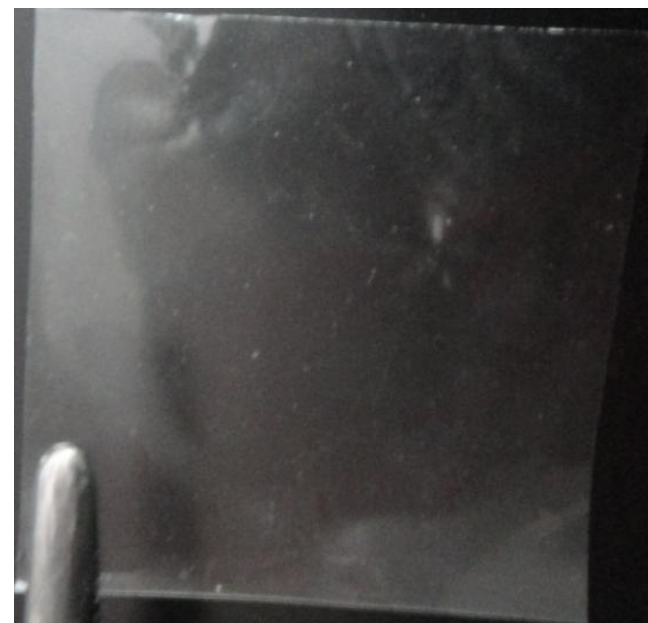

Figure 1: 6-MP oral thin film prepared by PVP-chitosan polymer complex

\section{FTIR Analysis}

IR spectra of 6-MP and Chitosan-PVP showed the prominent peaks for functional group like $\mathrm{N}-\mathrm{H}, \mathrm{C}-\mathrm{H}$ (aliphatic and aromatic), $\mathrm{C}-\mathrm{O}$ and $\mathrm{S}-\mathrm{H}$. Fundamental vibrations of primary functional groups and its frequency $\left(\mathrm{cm}^{-1}\right)$ of 6-MP, PVP-chitosan and 6-MP loaded PVPChitosan thin films are depicted in Figure $3 a, 3 b$, and $3 c$. Rresults suggests that on comparing the 6-mp films with PVP-Chitosan films, there is no interaction between the 6$\mathrm{mp}$ and PVP-Chitosan polymer complex which is confirmed by the preence of prominent peaks of functional groups and absence of any additional functional groups. (Figure 3 and Table 1). 


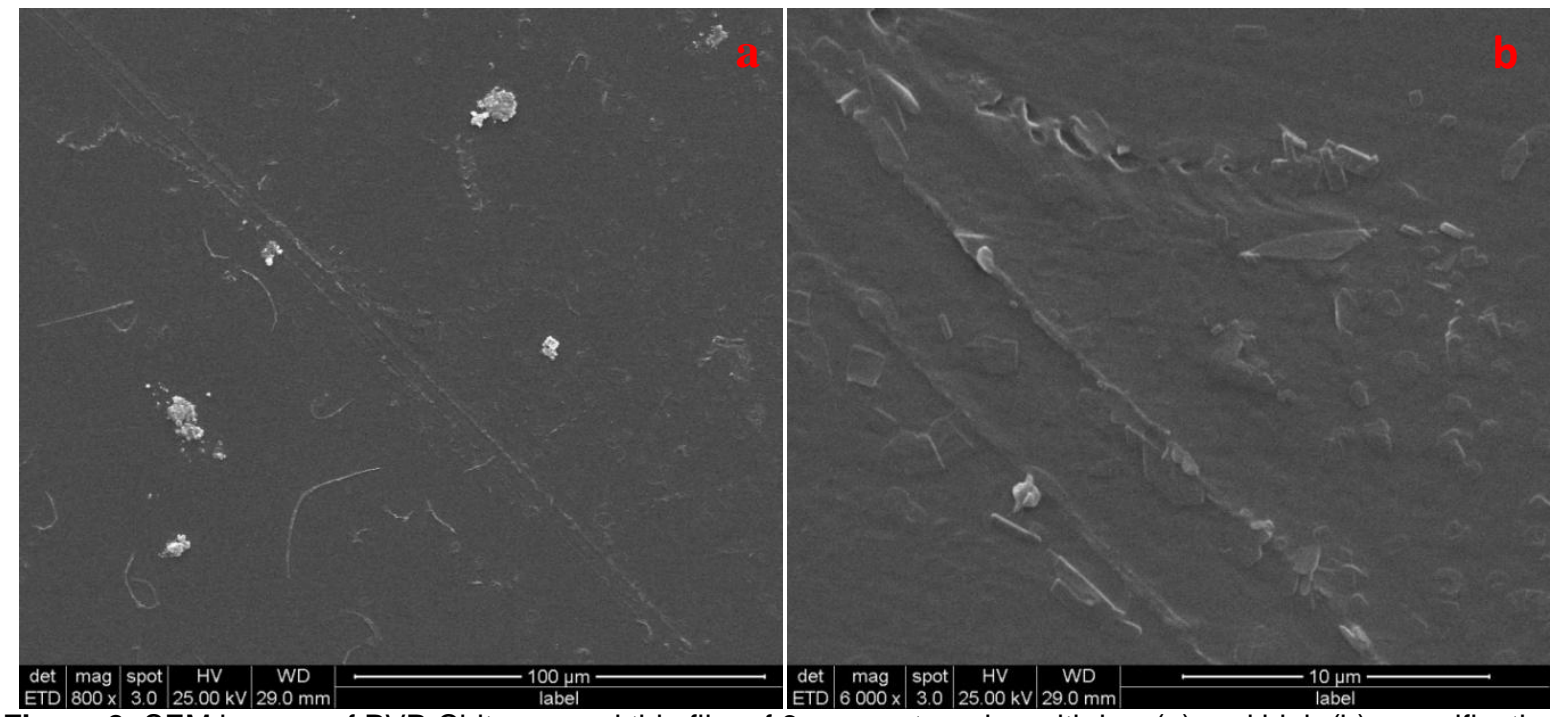

Figure 2: SEM images of PVP-Chitosan oral thin film of 6-mercaptopurine with low (a) and high (b) magnification

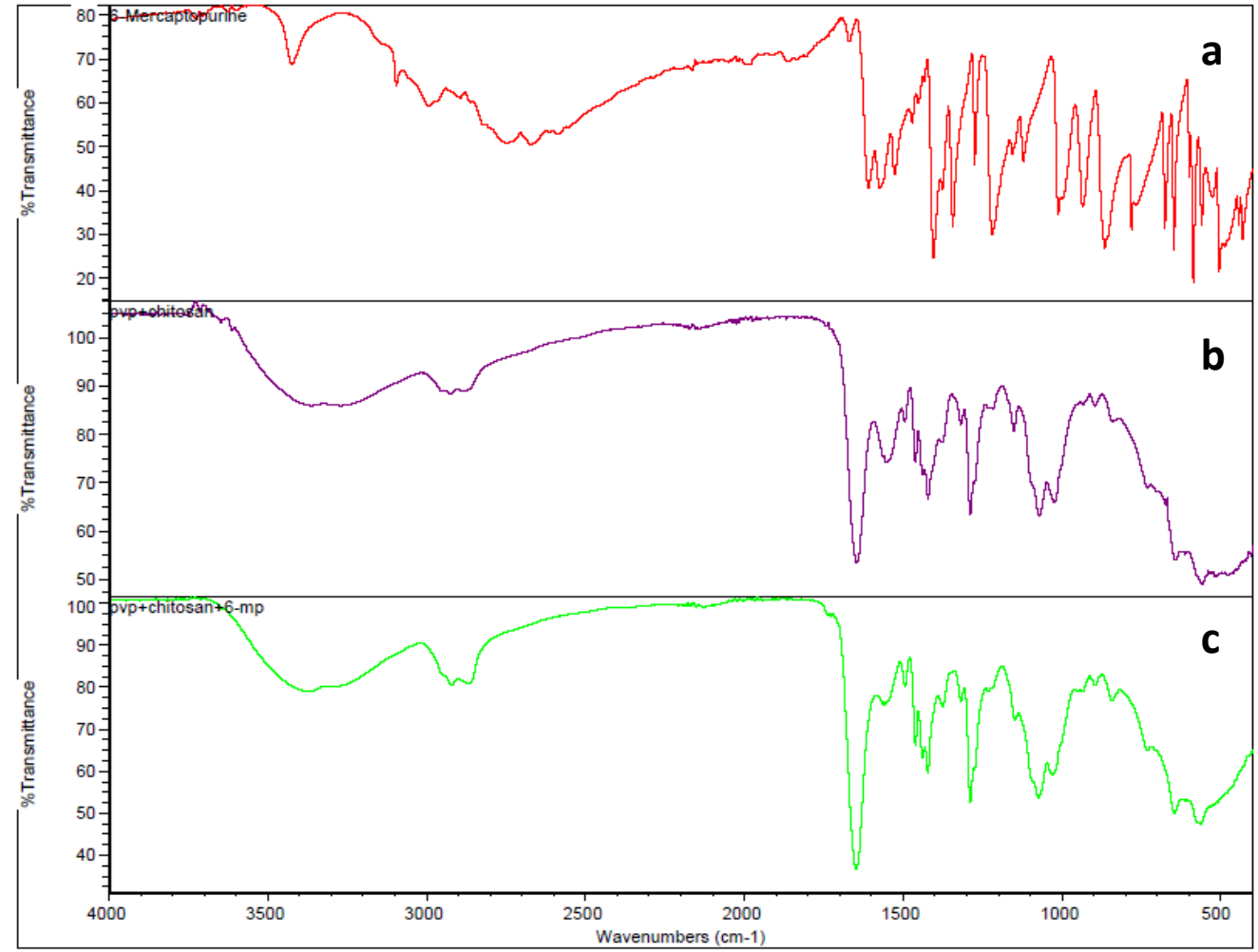

Figure 3: IR spectra of a) 6-mercaptopurine, b) PVP-Chitosan and c) 6-Mercaptopurine loaded PVP-Chitosan thin film

Table1: IR spectroscopic fundamental vibrations and frequencies $\left(\mathrm{cm}^{-1}\right)$ of 6-MP, PVP-Chitosan and 6-MP thin film

\begin{tabular}{cccccc}
\hline & \multicolumn{2}{c}{ PVP-Chitosan } & \multicolumn{2}{c}{ 6-MP thin film } \\
\hline $\begin{array}{c}\text { Fundamental } \\
\text { Vibrations }\end{array}$ & $\begin{array}{c}\text { Frequency } \\
\left(\mathbf{c m}^{-1}\right)\end{array}$ & $\begin{array}{c}\text { Fundamental } \\
\text { Vibrations }\end{array}$ & $\begin{array}{c}\text { Frequency } \\
\left(\mathbf{c m}^{-1}\right)\end{array}$ & $\begin{array}{c}\text { Fundamental } \\
\text { Vibrations }\end{array}$ & $\begin{array}{c}\text { Frequency } \\
\left(\mathbf{c m}^{-1}\right)\end{array}$ \\
\hline $\mathrm{N}-\mathrm{H}$ (stretch) & 3424.27 & $\mathrm{~N}-\mathrm{H}$ (stretch) & 3352.38 & $\mathrm{~N}-\mathrm{H}$ (stretch) & 3419.28 \\
$\mathrm{~N}-\mathrm{H}$ (Bend) & 1527.17 & $\mathrm{~N}-\mathrm{H}$ (Bend) & 1590.59 & $\mathrm{~N}-\mathrm{H}$ (Bend) & 1568.79 \\
$\mathrm{C}-\mathrm{H}$ (stretch) & $3095.11,2994.48$ & $\mathrm{C}-\mathrm{H}$ (stretch) & 2871.53 & $\mathrm{C}-\mathrm{H}($ stretch) & $3095.13,2994.04$ \\
$\mathrm{C}-\mathrm{N}$ & 1343.98 & $\mathrm{C}-\mathrm{N}$ & 1024.39 & $\mathrm{C}-\mathrm{N}$ & 1343.91 \\
$\mathrm{C}=\mathrm{N}$ & 1609.31 & $\mathrm{O}-\mathrm{H}$ & 3200 & $\mathrm{C}-\mathrm{O}$ & 1011.73 \\
$\mathrm{C}=\mathrm{C}$ & 1669.70 & $\mathrm{C}-\mathrm{O}$ & 1377.28 & $\mathrm{~S}-\mathrm{H}$ & 2672.36 \\
$\mathrm{~S}-\mathrm{H}$ & 2672.65 & & & & \\
\hline
\end{tabular}




\section{Prem Kumar et alo,}

\section{Surface $\mathrm{pH}$}

The surface $\mathrm{pH}$ of oral films has been determined in order to investigate the effect of $\mathrm{pH}$ on oral mucosa (Prem Kumar et al., 2014). The determined surface $\mathrm{pH}$ of the 6 MP film was in range of $6.7 \pm 0.1$, which was almost neutral and irritation free to the mucosal lining of the oral cavity.

\section{Thickness}

The films were evaluated for thickness using digital Vernier calipers and mean value was found to be $0.436 \pm 0.003 \mathrm{~mm}$ which indicates the uniformity of the film (Raju et al., 2011).

\section{Folding Endurance}

Folding endurance helps in determining the mechanical strength of the films. Higher the folding endurance higher is the mechanical strength (Semalty et al., 2008). The folding endurance of the drug loaded films was 560 which signifies that these films are strong enough to handle.

\section{Swelling Percentage (S\%)}

Penetration of solvent into the polymer matrix leads to increased weight of the films and facilitates diffusion of drug molecules from bulk of the matrix to external environment (Brazel and Peppas, 2000). The mean swelling percentage was found to be $30.63 \%$. These results imply that the absorption of water by these films was considerable for the drug release. Indeed higher swelling properties can cause discomfort in oral cavity due to their bulk properties.
Sci. Technol. Arts Res. J., April-June 2014, 3(2): 63-67

\section{In Vitro Disintegration Time}

Disintegration time gives an indication about onset of action which is desirable for oral thin films (Mishra and Amin, 2009). The calculated mean time for the film to disintegrate into complete fine particles was 0.36 minute and to completely disappear into the solution was 1.21 minute. These values indicate that these films have optimum disintegration time.

\section{In Vitro Drug Release Studies}

In order to investigate 6-MP release behaviour of PVPChitosan thin films, the thin films were incubated in different release media (phosphate buffer $\mathrm{pH}: 3.4,6.4$ and 7.4) and assessed by double beam UV-visible spectrophotometer. Figure 4 demonstrates 6-MP release profiles up to $48 \mathrm{~h}$ of incubation period. As shown in Figure 4 , PVP-Chitosan thin films showed an initial burst release of 6-MP in a period of 4-6 $\mathrm{h}$ for all incubation media (Aydin and Pulat, 2012). After this initial burst effect, a slower sustained and controlled release occurred throughout the incubation period. Cumulative drug release profiles of 6 MP thin film at $\mathrm{pH} 3.4$ (62\%), 6.4 (72\%) and 7.4 (82\%); were better than release profiles of pure drug (46\%, $48 \%$ and $45 \%$ ) (Fig $4 \mathrm{a}, 4 \mathrm{~b}$ and $4 \mathrm{c}$ ). We could also observe significant fall in concentration of 6-MP pure drug ( $\mathrm{pH} 3.4)$ from 16 hrs onwards, when compared to 6-MP thin film, whereas at $\mathrm{pH} 6.4$ and 7.4 there was no sudden decline in concentration. Release profiles supported that 6-MP molecules were encapsulated among the positively charged hydrophilic chains.

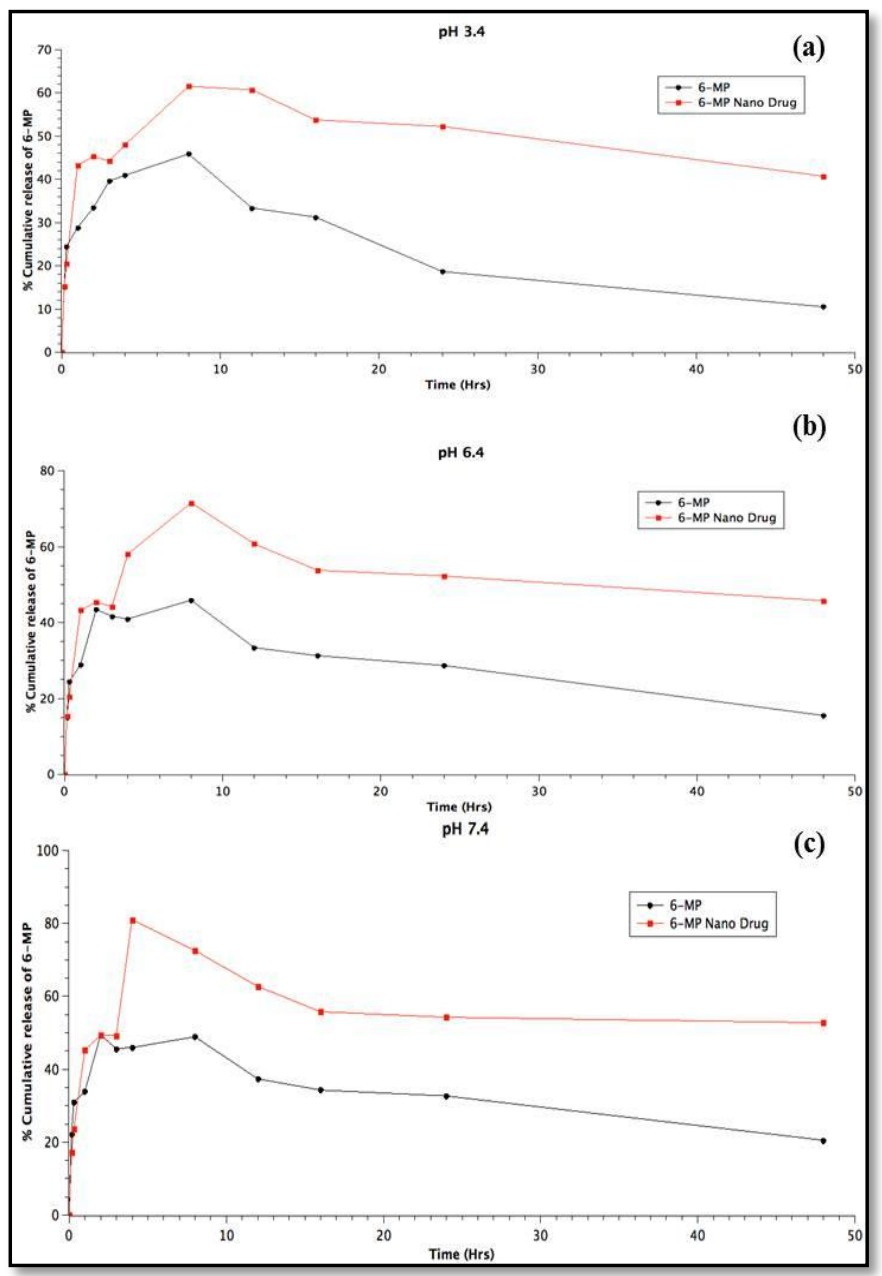

Figure 4: In vitro drug release of 6-MP from PVP-Chitosan thin film at $\mathrm{pH}$ a) 3.4 b) 6.4 c) 7.4 
Prem Kumar et al.,

\section{CONCLUSIONS}

In this study, we prepared 6-MP loaded PVP-Chitosan thin films for enhanced drug delivery. Results of the SEM images confirmed decreased size of the drug in the film. FTIR spectrum showed non-interaction of 6-MP and PVPChitosan polymer matrix. In vitro drug release of 6-MP from the thin film has enhanced to a considerable extent. So these formulations can be an alternative for delivering 6-MP, which could enhance solubility, bioavailability with its sustaining drug release process. The preparation of drug loaded PVP-chitosan films is a simple technique that can be easily scaled up.

\section{ACKNOWLEDGEMENTS}

All the authors are thankful to Department of Veterinary Pharmacology and Toxicology, Veterinary College, Bangalore and Nano Research for Advanced Materials and Technologies (NRT), Bangalore, for providing all facilities and support to carry out present work.

\section{REFERENCES}

Aydin, R.S.T., Pulat, M. (2012). 5-Fluorouracil Encapsulated Chitosan Nanoparticles for $\mathrm{pH}$-Stimulated Drug Delivery: Evaluation of Controlled Release Kinetics. Journal of Nanomaterial Article ID 313961.

Brazel, C.S., Peppas, N.A. (2000). Modeling of drug release from swellable polymers, European Journal of Pharmaceutics and Biopharmaceutics 49: 47-58.

Cheok, M.H., Evans, W.E. (2006). Acute lymphoblastic leukaemia: a model for the pharmacogenomics of cancer therapy. Nature Reviews Cancer 6: 117.

Cuin, A., Massabni, A.C., Pereira, G.A., Leite, C.Q.F., Pavan, F.R., Costa, R.S., Heinrich, T.A., Costa-Neto, C.M. (2011). 6-mercaptopurine complexes with silver and gold ions: Anti-tuberculosis and anti-cancer activities. Biomedicine and Pharmacotherapy 65: 334-338.

Estlin, E.J. (2001). Continuing therapy for childhood acute lymphoblastic leukaemia: clinical and cellular pharmacology of methotrexate, 6-mercaptopurine and 6thioguanine. Cancer Treatment Reviews 27: 351-363.

Karim, H., Ghalali, A., Lafolie, P.S., Vitols, S., Fotoohi, A.K. (2013). Differential role of thiopurine methyltransferase in the cytotoxic effects of 6-mercaptopurine and 6thioguanine on human leukemia cells. Biochemical and Biophysical Research 437: 280-286.

Kevadiya, B.D., Patel, T.A., Jhala, D.D., Thumbar, R.P., Brahmbhatt, H., Pandya, M.P., Rajkumar, S., Joshi, G.V., Gadhia, P.K., Tripathi, C.B. and Bajaj, H.C., 2012. Layered inorganic nanocomposites: a promising carrier for 5-fluorouracil (5-FU). European Journal of Pharmaceutics and Biopharmaceutics 81: 91.

Manohara, C., Jagadeesh, S.S., Prem, K.G., Swamy, K.B., Phani A.R. (2014). Improved Dissolution rate of Piroxicam by fusion solid dispersion technique. Science, Technology and Arts Research Journal 3(1): 44-47.
Sci. Technol. Arts Res. J., April-June 2014, 3(2): 63-67

Mawatari, H., Unei, K., Nishimura, S., Sakura, N., Ueda, K. (2001). Comparative pharmacokinetics of oral 6mercaptopurine and intravenous 6-mercaptopurine riboside in children. Pediatrics International 43: 673-677.

Mishra, R., Amin, A. (2009). Formulation development of taste masked rapidly dissolving films of cetirizine hydrochloride. Pharmaceutical Technology 33(2): 48-56.

Mona, N., Mayank, N., Vikram, C. (2012). Formulation and evaluation of mouth dissolving film of antipsychotic drug aripiprazole. Der Pharmacia Lettre 4(4): 1221-1227.

Panetta, J.C., Evans, W.E., Cheok, H. (2006). Mechanistic mathematical modelling of mercaptopurine effects on cell cycle of human acute lymphoblastic leukaemia cells. British Journal of Cancer 94: 93-100.

Podsiadlo, P., Sinani, V.A., Bahng, J.H., Kam, N.W.S., Lee, J., Kotov, N.A. (2008). Gold Nanoparticles Enhance the Anti-Leukaemia Action of a 6-mercaptopurine Chemoherapeutic Agent. Langmuir 24: 568.

Prem Kumar, G., Phani, A.R., Prasad, R.G.S.V., Sanganal, J.S., Manali, N., Gupta, R., Rashmi, N., Prabhakara, G.S., Paul Salins, C., Sandeep, K., Raju, D.B. (2014). Polyvinylpyrrolidone oral films of enrofloxacin: Film characterization and drug release. International Journal of Pharmaceutics 471: 146-152.

Raju, S., Sandeep, R.P., Anirudh, K.V., Deepthi, A., Sreeramulu, R.K., Madhava, R.P.V. (2011). Flash release oral films of metoclopramide hydrochloride for pediatric use: Formulation and in-vitro evaluation. Journal of Chemical and Pharmaceutical Research 3(4): 636-646.

Semalty, M., Semalty, A., Kumar, G. (2008). Formulation and Characterization of Mucoadhesive Buccal Films of Glipizide. Indian Journal of Pharmaceutical Sciences 70(1): 43-48.

Senthil, V., Suresh K,R., Nagaraju, C.V.V., Jawahar, N., Ganesh, G.N.K., Gowthamarajan, K. (2010). Design and development of hydrogen nanoparticles for mercaptopurine. Journal of Advanced Pharmaceutical Technology and Research 1(3): 334-337.

Stuart, B. (2004). Infrared spectroscopy; Fundamentals and applications. John Wiley and Sons, Inc., USA.

Sun, H., Wang, T., Liu, X., CHEN, P. (2013). A sensitive inhibition chemiluminescence method for the determination of 6-mercaptopurine in tablet and biological fluid using the reaction of luminol-Ag (III) complex in alkaline medium. Journal of Luminescence 134: 154-159.

The United States Pharmacopoeia- National Fomulary-21, Asian Edn., U.S. Pharmacopoeial convention Inc Rockville MD. 2009, 726-727.

Wang, D.M., Wu, T.T., Lin, F.C., Hou, J.Y., Lai, J.Y. (2000). A novel method for controlling the surface morphology of polymericmembranes. Journal of Membrane Science 169(1): 39-51: 2000.

Zacchigna, M., Cateni, F., Di-Luca, G., Drioli, S. (2007). A simple method for the preparation of PEG-6mercaptopurine for oral administration. Bioorganic and Medicinal Chemistry Letters 17: 6607-6609. 